\title{
KẾT QUẢ SAU ĐIỀU TRỊ PHẪU THUẬT THÔNG LIÊN THẤT CÓ TĂNG ÁP LỰC ĐỘNG MẠCH PHỔI NẬNG Ở TRẺ EM TẠI TRUNG TÂM TIM MẠCH - BỆHH VIỆN E
}

Đinh Phưong Thảo ${ }^{1}$, Vũ Thị Chang ${ }^{1}$, Đỗ Anh Tiến ${ }^{2}$, Nguyến Trần Thủy ${ }^{2 *}$

\section{TÓM TẮT}

Mục tiêu: Mô tả đặc điểm lâm sàng, cận lâm sàng và đánh giá kết quả điều trị sớm và sau 3 tháng ở trẻ em sau phẫu thuật đóng Thông liên thất - tăng áp lực động mạch phổi nặng (TLTTALĐMPN) tại Trung tâm Tim mạch - Bệnh viện E (TTTM-BVE)

Đối tựng và phương pháp nghiên cứu: Nghiên cứu mô tả, tiến cứu kết hợp hồi cứu trên 60 bệnh nhân $(\mathrm{BN})$ được chẩn đoán TLTTALĐMPN tại TTTM - BVE từ tháng 8/2018 đến tháng $3 / 2021$.

Kết quả nghiên cứu: $60 \mathrm{BN}$ đủ tiêu chuẩn nghiên cứu; $59 \mathrm{BN}$ được phẫu thuật; tuổi trung bình là 8,98 tháng; cân nặng trung bình khi phẫu thuật là $5,49 \mathrm{~kg}$. $57 \mathrm{BN}(95,0 \%)$ suy tim độ II-III trước mổ, $43 \mathrm{BN}(71,7 \%)$ suy dinh dưỡng vừa nặng. Giá trị áp lực động mạch phổi trung bình trước mổ là 71,53 $\pm 9,42 \mathrm{mmHg}(60-90 \mathrm{mmHg})$. Kích thước lỗ thông trung bình 9,23 $\pm 3,32$ (6 $20 \mathrm{~mm})$. Thời gian chạy tuần hoàn ngoài cơ thể trung bình $67,8 \pm 24,5$ phút, cặp ĐMC trung bình 44,3 $\pm 20,4$ phút. Tỷ lệ tử vong sớm sau mổ 1 bệnh nhân $(1,7 \%), 14$ BN $(23,7 \%)$ còn shunt tồn lưu, 15 BN $(25,4 \%)$ bị block nhánh phảỉ, 1 BN (1,7\%) block AV III phải đặt máy tạo nhịp. Áp lực động

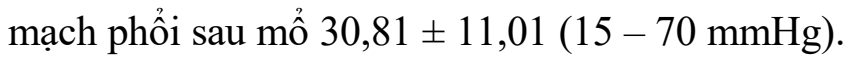
Theo dõi sau mổ trung bình 04 tháng: không có BN tử vong muộn, ALĐMP khi tái khám là 22,36 $\pm 7,83$ (15 - $50 \mathrm{mmHg})$. Nhóm trẻ được phẫu thuật trước 12 tháng tuổi cho thấy giá trị ALĐMP trở về mức bình thường sớm hơn nhóm trẻ được mổ sau 12 tháng $(89,6 \%$ với 50,0\%, p < 0,05). Có 53 bệnh nhân suy tim độ $\mathrm{I}(94,6 \%)$ và $41 \mathrm{BN}$ $(73,2 \%)$ có cân nặng bình thường theo tuổi thời điểm tái khám.

Kết luận: Phẫu thuật vá thông liên thất là phương pháp điều trị triệt để, tối ưu nhất những trường hợp thông liên thất có tăng áp lực động mạch phổi nặng. Nghiên cứu của chúng tôi cho thấy một kết quả ban đầu rất khả quan, tỷ lệ thành công là $98,3 \%$, tần suất xảy ra biến chứng thấp và đều được phát hiện xử lý kịp thời. Ở nhóm trẻ được phẫu thuật trước 12 tháng tuổi cho thấy tỷ lệ BN có giá trị ALĐMP trở về mức bình thường cao hơn nhóm trẻ được mổ sau 12 tháng tuổi.

Tù khóa: Thông liên thất, tăng áp lực động mạch phổi nặng, kết quả sau phẫu thuật tim bẩm sinh, 60 trẻ em, Trung tâm Tim mạch - Bệnh viện E

\section{SUMMARY}

SURGICAL RESULTS FOR CLOSURE OF VENTRICULAR SEPTAL DEFECT WITH SEVERE PULMONARY HYPERTENSION IN CHILDREN AT CARDIOVASCULAR CENTER - E HOSPITAL

Objectives: To describe the characteristics of clinical manifestations, laboratory and evaluation early treatment results and after 3

${ }^{I}$ Truoòng Đại học Y-Dượ, Đại học Thái Nguyên

${ }^{2}$ Trung tâm Tim mạch - Bệnh viện $E$

*Tác giả liên hệ: Nguyễn Trần Thủy;Email: drtranthuyvd@gmail.com: Ngày nhận bài: 17/08/2021 Ngày cho phép đăng:30/09/2021 
months in children who underwent surgery for Ventricular septal defect (VSD) closed - severe pulmonary hypertension $(\mathrm{PH})$ at Cardiovascular Center - E Hospital.

Subjects and Methods: A prospective and retrospective descriptive study on 60 patients diagnosed with VSD - severe pulmonary hypertension at Cardiovascular Center - E Hospital from 8/2018 to 3/2021.

Results: 60 patients in the study, 59 patients underwent surgery, the mean age was 8.98 months, the average weight was $5.49 \mathrm{~kg} .57$ patients $(95.0 \%)$ grade II-III heart failure before surgery, 43 patients $(71.7 \%)$ with moderate to severe malnutrition. The mean preoperative pulmonary artery pressure (PAP) was $71.53 \pm$ $9.42 \mathrm{mmHg}(60-90 \mathrm{mmHg})$. Average size of VSD was $9.23 \pm 3.32(6-20 \mathrm{~mm})$. Cardiopulmonary bypass/ the aortic cross-clamp times was $67,8 \pm 24,5 / 44,3 \pm 20,4$ minutes. There was 1 early deaths $(1,7 \%), 14(23,7 \%)$ with residual shunt, 15 patients $(25.4 \%)$ with right bundle branch block, 1 patient (1.7\%) AV block III requires a pacemaker. PAP after surgery was $30.81 \pm 11.01$ (15 - $70 \mathrm{mmHg})$.

Follow-up after surgery for an average of 3 months: there was no late death, PAP at followup was $22.36 \pm 7.83(15-50 \mathrm{mmHg})$. The group of children operated before 12 months, the percentage of patients PAP value returned to normal higher than the group of children operated after 12 months (89.6\% vs 50.0\%), statistical significance at $\mathrm{p}<0,05$. There were 53 patients with heart failure grade I $(94,6 \%)$ and 41 patients $(73.2 \%)$ had normal weight for age at the time of re-examination.
Conclusion: The surgery VSD closed is the most thorough and optimal treatment method for VSD with severe PH. Our study showed a good outcome after surgery, the success rate was $98.3 \%$, the frequency of complications was low and all were detected and treated promptly. In the group of children operated before 12 months, the percentage of patients PAP value returned to normal higher than the group of children operated after 12 months.

Key word: Ventricular septal defect, severe pulmonary hypertension, outcomes after congenital heart surgery, 60 children, Cardiovascular Center - E hospital

\section{I. ĐẶT VẤN ĐỀ}

Thông liên thất là dị tật tim bẩm sinh hay gặp nhất ở trẻ em, là bệnh lý điển hình của dạng tim bẩm sinh tồn tại luồng thông trái - phải, lỗ thông có thể tự đóng, đa phần với kích thước nhỏ, phần màng. Với TLT lỗ lớn, tăng áp lực động mạch phổi nặng (ALĐMP tâm thu tăng lớn hơn $50 \mathrm{mmHg}$ ) [3] khó có thể tự đóng, nhất là khi áp lực tuần hoàn phổi cao gần bằng áp lực tuần hoàn hệ thống thì tỷ lệ tự đóng dưới 5\% [5]. Phẫu thuật vá lỗ thông là phương pháp kinh điển để điều trị triệt để. Phẫu thuật vá lỗ TLT đơn thuần, ALĐMP chưa tăng cao có tỷ lệ thành công rất cao lên tới 100\%. [19] [13]. Tuy nhiên phẫu thuật vá thông liên thất ở nhóm trẻ có tăng áp lực động mạch phổi nặng bao giờ cũng đầy thách thức và khó khăn.

Tại Trung tâm Tim mạch - Bệnh viện E, TLT là một trong những bệnh tim bẩm sinh thường gặp nhất, phẫu thuật đóng thông liên thất được thực hiện thường xuyên trong đó nhiều trẻ bị thông liên thất có tăng áp lực động mạch phổi 
nặng. Do đó chúng tôi tiến hành nghiên cứu nhằm tìm hiểu đặc điểm lâm sàng, cận lâm sàng và đánh giá kết quả điều trị sau phẫu thuật của nhóm trẻ này.

\section{II. ĐỐI TƯợNG VÀ PHƯƠNG PHÁP NGHIÊN CÚUU}

Nghiên cứu mô tả cắt ngang, trẻ dưới 16 tuổi được chẩn đoán TLT có TALĐMP nặng tại Trung tâm Tim mạch - Bệnh viện $\mathrm{E}$ từ tháng 08/2018 đến 03/2021.

Tiêu chuẩn lựa chọn: Được chẩn đoán TLT trên siêu âm doppler tim và đo ALĐMPTT > 50 mmHg trên siêu âm Doppler tim hoặc ALĐMPTT/ALĐMHT tâm thu $\geq 0,65$.

Tiêu chuẩn loại trừ: chúng tôi loại trừ những bệnh nhân TLT trong những tổn thương tim phức tạp khác như: ống nhĩ thất chung, tứ chứng Fallot, đảo gốc các mạch máu lớn, thất phải hai đường ra... những trường hợp TLT thứ phát: sau thông tim, chấn thương tim, nhồi máu cơ tim...

Đánh giá trước mổ gồm lâm sàng, siêu âm Doppler tim, điện tim, Xquang ngực. Vật liệu sử dụng trong phẫu thuật là miếng vá Xenosure. Dữ kiện trong mổ được ghi nhận bao gồm: phương pháp mổ, thời gian chạy tuần hoàn ngoài cơ thể, thời gian cặp động mạch chủ, đặc điểm lỗ thông khi mổ. Sau phẫu thuật bệnh nhân được đánh giá bằng lâm sàng, siêu âm Doppler tim và các thuốc điều trị sau mổ. Diễn biến trong quá trình phẫu thuật, kết quả, biến chứng được thống kê, phân tích, so sánh từ đó đưa ra nhận xét về đặc điểm tổn thương, kết quả sớm và trung hạn của phẫu thuật.

Xử lí số liệu: số liệu được thu thập, quản lý và xử lý bằng các thuật toán thống kê y học với phần mềm SPSS 25.0

\section{KẾT QUẢ}

\section{1. Đặc điểm chung của bệnh nhân}

Trong thời gian từ tháng $08 / 2018$ đến tháng 03/2021, có 60 trẻ được chẩn đoán TLT TALĐMP nặng đủ các tiêu chuẩn nghiên cứu với các đặc điểm sau: tuổi trung bình của $\mathrm{BN}$ là 8,98 tháng, tỷ lệ nam/nữ tương đương nhau 48,3/51,7\% (29/31 BN), cân nặng trung bình khi mổ $5,49 \mathrm{~kg}(2,5-25 \mathrm{~kg})$.

\section{2. Đặc điểm lâm sàng, cận lâm sàng}

Bảng 1: Đặc điểm lâm sàng của bệnh nhân truớc phẫu thuật

\begin{tabular}{|c|l|c|c|}
\hline \multicolumn{2}{|c|}{ Đặc điểm lâm sàng } & $\mathbf{n}$ & $\mathbf{\%}$ \\
\hline \multirow{4}{*}{ Triệu chứng lâm sàng } & Khó thở & 55 & 91,7 \\
\cline { 2 - 4 } & Chậm tăng cân & 41 & 68,3 \\
\cline { 2 - 4 } & Bú kém, vã mồ hôi & 37 & 61,6 \\
\cline { 2 - 4 } & Viêm phổi tái diễn & 21 & 35,0 \\
\cline { 2 - 4 } & Tiếng T2 mạnh & 43 & 71,7 \\
\cline { 2 - 4 } & Tiếng TTT mờ & 20 & 33,3 \\
\hline \multirow{2}{*}{ Mức độ suy tim } & Độ I & 3 & 5,0 \\
\cline { 2 - 4 } & Độ II -III & 57 & 95,0 \\
\hline \multirow{2}{*}{ Tình trạng suy dinh dưỡng } & Không SDD & 17 & 28,3 \\
\cline { 2 - 4 } & SDD vừa - nặng & 43 & 71,7 \\
\hline
\end{tabular}


Nhận xét: Triệu chứng lâm sàng hay gặp nhất là khó thở $91,7 \%, 41 \mathrm{BN}(68,3 \%)$ chậm tăng cân, 37 BN có bú kém vã mồ hôi (61,6 \%). 95\% bệnh nhân suy tim độ II-III. Số bệnh nhân suy dinh dưỡng vừa - nặng chiếm $71,7 \%$.

Bảng 2: Đặc điểm trên siêu âm tim trước mổ

\begin{tabular}{|c|c|c|c|}
\hline \multicolumn{2}{|c|}{ Các đặc điểm trên siêu âm tim } & $\mathbf{n}$ & $\%$ \\
\hline \multirow{5}{*}{ Vị trí lỗ thông } & Quanh màng & 50 & 83,3 \\
\hline & Phễu & 6 & 10,0 \\
\hline & Cơ bè & 2 & 3,3 \\
\hline & Buồng nhận & 1 & 1,7 \\
\hline & Quanh màng + cơ & 1 & 1,7 \\
\hline \multirow{2}{*}{$\begin{array}{l}\text { Kích thước } \\
\text { lỗ TLT(mm) }\end{array}$} & $\mathrm{TB} \pm \mathrm{SD}$ & \multicolumn{2}{|c|}{$9,23 \pm 3,32$} \\
\hline & Min - Max & \multicolumn{2}{|c|}{$6-20$} \\
\hline
\end{tabular}

Nhận xét: TLT phần quanh màng gặp ở $55 \mathrm{BN}(83,3 \%)$, phần phễu $6 \mathrm{BN}(10 \%), 2$ BN có lỗ thông phần cơ bè, 1 BN TLT phần buồng nhận, có 1 bệnh nhân có lỗ thông ở hai vị trí quanh màng + cơ.

Kích thước lỗ thông trên siêu âm lớn, trung bình $9,23 \pm 3,32 \mathrm{~mm}$, nhỏ nhất là $6 \mathrm{~mm}$, lớn nhất $20 \mathrm{~mm}$.

Bảng 3: Giá trị các thông số trên siêu âm tim trước mổ

\begin{tabular}{|c|l|l|l|c|}
\hline Các chỉ số (mm) & \multicolumn{1}{|c|}{$\begin{array}{c}\text { Nhỏ nhất } \\
\mathbf{( m m )}\end{array}$} & $\begin{array}{c}\text { Lớn nhất } \\
(\mathbf{m m})\end{array}$ & TB $\pm \mathbf{S D}$ & Z-score TB \\
\hline ĐK thất trái tâm trương & 16 & 45 & $27,3 \pm 6,3$ & 2,19 \\
\hline ĐK gốc động mạch phổi & 7 & 37 & $15,1 \pm 4,88$ & 3,04 \\
\hline Áp lực động mạch phổi & 60 & 95 & $71,53 \pm 9,42$ & - \\
\hline
\end{tabular}

Nhận xét: Đường kính thất trái cuối tâm trương và đường kính gốc ĐMP giãn, Zscore theo cân nặng trung bình đều $>2$.

Giá trị áp lực ĐMP tăng nặng - rất nặng, trung bình 71,53 $\pm 9,42$, nhỏ nhất là $60 \mathrm{mmHg}$, lớn nhất $95 \mathrm{mmHg}$.

\subsection{Kết quả phẫu thuật sớm và trung hạn}

Bảng 4: Đặc điểm trong quá trình phẫu thuật và thời gian điều trị

\begin{tabular}{|l|l|c|c|}
\hline \multicolumn{2}{|c|}{ Đặc điểm } & n & \% \\
\hline \multirow{2}{*}{ Phương pháp phẫu thuật } & Mổ ít xâm lấn & 35 & 59,3 \\
\cline { 2 - 4 } & Mổ đường giữa & 24 & 40,7 \\
\hline \multirow{2}{*}{ Thời gian cặp động mạch chủ (phút) } & $\bar{X} \pm$ SD & $44,3 \pm 20,4$ \\
\cline { 2 - 3 } & Min- max & $15-90$ \\
\hline \multirow{2}{*}{ Thời gian chạy tuần hoàn ngoài cơ thể (phút) } & $\bar{X} \pm$ SD & $67,8 \pm 24,5$ \\
\cline { 2 - 3 } & Min - max & $30-120$ \\
\hline
\end{tabular}

Nhận xét: Đa số bệnh nhân được phẫu thuật ít xâm lấn qua đường mở ngực nhỏ (56,6\%). 
Thời gian cặp ĐMC trung bình 44,3 $\pm 20,4$ phút, ngắn nhất 15 phút, dài nhất là 90 phút. Thời gian chạy tuần hoàn ngoài cơ thể trung bình $67,8 \pm 24,5$ phút. Ngắn nhất là 30 phút, lâu nhất 120 phút.

Bảng 5: Các biến chứng sau mổ

\begin{tabular}{|c|c|c|c|}
\hline \multicolumn{2}{|c|}{ Biến chứng } & $\mathbf{n}$ & $\%$ \\
\hline \multicolumn{2}{|c|}{ Shunt tồn lưu } & 14 & 23,7 \\
\hline \multirow{3}{*}{$\begin{array}{l}\text { Rối loạn } \\
\text { nhịp tim }\end{array}$} & Block nhánh phải không hoàn toàn & 15 & 25,4 \\
\hline & Block nhánh phải hoàn toàn & 2 & 3,4 \\
\hline & Block AV III có đặt máy tạo nhịp & 1 & 1,7 \\
\hline \multicolumn{2}{|c|}{ Nhiễm trùng vết mổ } & 5 & 8,5 \\
\hline \multicolumn{2}{|l|}{ Liệt cơ hoành } & 2 & 3,4 \\
\hline \multicolumn{2}{|c|}{ Cơn tăng áp phổi sau mổ } & 1 & 1,7 \\
\hline \multicolumn{2}{|c|}{ Chảy máu sau mổ } & 2 & 3,4 \\
\hline \multicolumn{2}{|l|}{ Tử vong sớm } & 1 & 1,7 \\
\hline
\end{tabular}

Nhận xét:

Trong tổng số 59 trẻ được phẫu thuật có 1 trẻ tử vong sớm $(1,7 \%)$.

Tỷ lệ shunt tồn lưu gặp ở 23,7\%. Rối loạn nhịp tim ở 18 bệnh nhân (30,5\%), trong đó block nhánh phải không hoàn toàn 15 bệnh nhân $(25,4 \%)$, block nhánh phải hoàn toàn 2 bệnh nhân $(3,4 \%)$, block AV cấp III có đặt máy tạo nhịp 1 bệnh nhân $(1,7 \%)$. Nhiễm trùng vết mổ phải làm sạch, khâu lại gặp ở 5 bệnh nhân $(8,3 \%), 2$ bệnh nhân liệt cơ hoành $(3,4 \%)$ đã được phẫu thuật khâu gấp nếp, 2 bệnh nhân chảy máu sau mổ phải phẫu thuật lại $(3,4 \%), 1$ bệnh nhân có cơn tăng áp phổi sau mổ được điều trị bằng Sidenafil đường tĩnh mạch. Tất cả bệnh nhân này đều ổn định trước khi ra viện.

Bảng 6: Thay đổi ALĐMPTT trên siêu âm tim khi khám lại

\begin{tabular}{|l|c|c|}
\hline ALĐMPTT (mmHg) & $\overline{\mathbf{x}} \pm \mathbf{S D}$ & $\mathbf{p}$ \\
\hline Siêu âm trước mổ & $71,41 \pm 9,14$ & \multirow{2}{*}{$<0,05$} \\
\hline Siêu âm khi ra viện & $33,18 \pm 10,27$ & \\
\hline Siêu âm khi khám lại & $23,96 \pm 7,53$ & \\
\hline
\end{tabular}

Nhận xét: Giá trị áp lực động mạch phổi trên siêu âm tim giảm rõ rệt giữa các thời điểm, có ý nghĩa thống kê $(\mathrm{p}<0,05)$ 
Bảng 7: So sánh tỷ lệ ALĐMP trở về bình thuờng khi khám lại giữa 2 nhóm đự̛̣c mổ truớc và sau 12 tháng tuổi

\begin{tabular}{|c|c|c|c|c|c|}
\hline \multirow{2}{*}{ Mức ALĐMP (mmHg) Thò̀i điểm } & \multicolumn{2}{|c|}{$<12$ tháng } & \multicolumn{2}{|c|}{$\geq 12$ tháng } & \multirow{2}{*}{$\mathbf{p}$} \\
\hline & $\mathbf{n}$ & $\%$ & $\mathbf{n}$ & $\%$ & \\
\hline$<30$ & 43 & 89,6 & 4 & 50,0 & \multirow{3}{*}{$<0,05$} \\
\hline $30-<50$ & 4 & 8,3 & 3 & 37,5 & \\
\hline$\geq 50$ & 1 & 2,1 & 1 & 12,5 & \\
\hline Tổng số & 48 & 100,0 & 8 & 100,0 & \\
\hline
\end{tabular}

Nhận xét: Ở nhóm trẻ được mổ trước 12 tháng có 89,6\% ALĐMP trở về bình thường khi khám lại, cao hơn nhóm trẻ được mổ sau 12 tháng tuổi $(50,0 \%)(\mathrm{p}<0,05)$.

Bảng 8: Tình trạng suy tim và suy dinh dữ̃ng khi khám lại (n=56)

\begin{tabular}{|c|c|c|c|c|c|c|}
\hline \multirow{2}{*}{\multicolumn{2}{|c|}{ Đặc điểm }} & \multicolumn{2}{|c|}{ Trước mổ } & \multicolumn{2}{|c|}{ Khi khám lại } & \multirow{3}{*}{$\begin{array}{c}\mathbf{p} \\
<0,001\end{array}$} \\
\hline & & \multirow{2}{*}{$\begin{array}{l}\mathbf{n} \\
2\end{array}$} & \multirow{2}{*}{$\begin{array}{c}\% \\
3,6\end{array}$} & \multirow{2}{*}{$\begin{array}{c}\mathbf{n} \\
53\end{array}$} & \multirow{2}{*}{$\begin{array}{c}\% \\
94,6\end{array}$} & \\
\hline Suy tim & Độ I & & & & & \\
\hline & Độ II-III & 54 & 96,4 & 3 & 5,3 & $<0,001$ \\
\hline \multirow{2}{*}{$\begin{array}{l}\text { Suy dinh } \\
\text { dưỡng }\end{array}$} & Không SDD & 16 & 28,6 & 41 & 73,2 & $<0,05$ \\
\hline & SDD vừa-nặng & 40 & 71,4 & 15 & 26,8 & $<0,05$ \\
\hline
\end{tabular}

Nhận xét: Tỷ lệ bệnh nhân suy tim độ II-III giảm rõ rệt so với thời điểm trước mổ $(\mathrm{p}<0,05)$

Tỷ lệ bệnh nhân không suy dinh dưỡng tăng cao so với thời điểm trước mổ $(\mathrm{p}<0,05)$

\section{BÀN LUẬnN}

\section{1. Đặc điểm chung}

Tuổi: Trong 59 bệnh nhân được phẫu thuật, tuổi trung bình là 8,98 tháng (lớn nhất là 144 tháng, nhỏ nhất là 01 tháng), trong đó $48 \mathrm{BN}$ $(81,4 \%)$ được mổ trước 12 tháng tuổi, $54 \mathrm{BN}$ $(91,5 \%)$ được mổ trước 24 tháng tuổi. Điều này phù hợp với quan điểm của nhiều tác giả nhằm ngăn chặn sự tiến triển của bệnh lí mạch máu phổi [4] [11].

Numan Ali Aydemir (2013) còn cho rằng ở những trẻ TLT-TALĐMP nặng, nên phẫu thuật sửa chữa sớm dưới ba tháng để được kết quả tốt nhất [6]. Số $\mathrm{BN}$ được mổ trước độ tuổi đến trường là $58(98,3 \%)$ điều này tránh ảnh hưởng đến tâm lí và việc học tập của trẻ. Cùng với đó, trong những năm gần đây, việc triển khai rộng rãi và đồng bộ phương pháp siêu âm tim từ tuyến $\mathrm{y}$ tế trung ương đến các tuyến y tế cơ sở giúp cho việc khám sàng lọc bệnh tim bẩm sinh trong đó có TLT dễ dàng hơn. Do đó số lượng trẻ em được phát hiện bệnh ngày càng sớm hơn, được theo dõi quản lý tốt hơn và dễ được tiếp cận sớm với phương pháp điều trị triệt để. Nhóm trẻ lớn chiếm tỷ lệ thấp, tuy nhiên điều này phản ánh đây chính 
là những đối tượng bệnh nhân bị bỏ sót trong giai đoạn trước đây khi công tác sàng lọc chưa được triển khai phổ biến.

Giới: Số trẻ trai là 29 (48,3\%), trẻ gái 31 (51,7\%), tỉ lệ nam/nữ không có sự khác biệt nhiều, nhận xét này cũng phù hợp với nhiều tác giả trong và ngoài nước [9] [12] [1].

\section{2. Đặc điểm trước phẫu thuật}

\section{Triệu chứng lâm sàng}

Trong nghiên cứu của chúng tôi, triệu chứng cơ năng của đối tượng nghiên cứu khá đa dạng, bao gồm khó thở, Bú kém vã mồ hôi, chậm tăng cân, đau ngực, viêm phổi tái diễn. Tỷ lệ bệnh nhân có triệu chứng cơ năng khi đến viện là 95,0\%, trong đó triệu chứng hay gặp nhất là khó thở $(91,7 \%)$, chậm tăng cân $(68,3 \%)$, bú kém vã mồ hôi $(61,6 \%)$, triệu chứng đau ngực chúng tôi chỉ gặp $5 \%$ và ghi nhận được ở nhóm trẻ lớn (Bảng 1). Cũng theo Aydemir N. A và Vaidyanathan $\mathrm{B}$ triệu chứng hay gặp nhất là khó thở [6] [20]. Triệu chứng cơ năng ở bệnh nhân TLT đa dạng và khác nhau ở các nhóm tuổi, tuy nhiên không có triệu chứng nào đặc hiệu trong bệnh TLT. Những biểu hiện trên hay gặp ở những bệnh nhân tim bẩm sinh có luồng thông trái-phải khác, tuy nhiên các triệu chứng này lại gợi ý rất nhiều cho việc chỉ định cận lâm sàng tiếp theo giúp chẩn đoán xác định từ đó có chiến lược theo dõi và điều trị cụ thể.

21 bệnh nhân (35\%) bị viêm phổi tái diễn nhiều đợt trước khi mổ, tỷ lệ này thấp hơn so với một số nghiên cứu khác, theo Tăng Hùng Sang (2010) có $51 \%$ trẻ từng bị viêm phổi từ 3 lần trở lên, tuổi trung bình khi phẫu thuật là 37,24 tháng [2]. Do trong nghiên cứu của chúng tôi đa phần trẻ được phát hiện sớm, được theo dõi và quản lý bằng thuốc, nhóm trẻ nhỏ chiếm tỷ lệ cao, trẻ $<6$ tháng tuổi có $41 \mathrm{BN}$ chiếm $68,3 \%$, có nhiều trẻ còn chưa từng bị viêm phổi trước đó.

Theo nhiều tác giả các triệu chứng cơ năng khi đã TALĐMP cố định là tím đối xứng, đôi khi xuất hiện ho máu, ngất [11] [15], tuy nhiên chúng tôi không gặp trường hợp nào. Trong nghiên cứu có $1 \mathrm{BN} 12$ tuổi, TALĐMP rất nặng, kết quả siêu âm là shunt 2 chiều chủ yếu T-P, nên các triệu chứng trên chúng tôi chưa ghi nhận được. 59 BN còn lại đều chưa đến giai đoạn TALĐMP cố định, shunt 1 chiều T-P trên siêu âm doppler tim.

Đối với TLT có TALĐMP nặng khi nghe tim sẽ thấy tiếng T2 mạnh ( tiếng đóng van ĐMP) và nhất là khi ALĐMP tăng cao sấp xỉ bằng ALĐMHT thì không còn sự chênh áp giữa 2 buồng thất qua lỗ thông chính vì vậy tiếng thổi tâm thu ở khoang liên sườn III, IV cạnh ức trái sẽ ngắn lại, nghe không rõ. Trong số BN nghiên cứu của chúng tôi có $43 \mathrm{BN}(71,7 \%)$ có tiếng $\mathrm{T} 2$ mạnh và tiếng thổi tâm thu < 3/6 xuất hiện ở 20 BN (33,3\%).

Phân độ mức độ suy tim theo ROSS cải biên ở nhóm trẻ nhỏ. Số BN suy tim độ II là 32 (53,3\%), độ III là 25 (41,7\%), không có $\mathrm{BN}$ nào độ IV, có 3 BN (5,0\%) suy tim độ I. Tác giả Lê Ngọc Sơn (2007) báo cáo trên 123 BN TLT TALĐMP nặng có 117 BN $(95,9 \%)$ suy tim độ II-III, 4,1\% suy tim độ I [3]. Kết quả tương đương với nghiên cứu của chúng tôi. Tình trạng suy tim là một trong những yếu tố đóng vai trò quyết định trong chỉ định phẫu thuật, chỉ định phẫu thuật ở trẻ $<6$ tháng tuổi khi điều trị nội khoa không đáp ứng, không khống chế được tình trạng suy tim [5] [15]. 
Chúng tôi thông kê được $43 \mathrm{BN}(71,7 \%)$ có suy dinh dưỡng vừa - nặng trước mổ. Tăng Hùng Sang (2010) có 89\% trẻ bị SDD [2], Nguyễn Quang Minh 2018 (61\%) [1]. Đây là một dấu hiệu quan trọng được nhiều tác giả quan tâm, là hậu quả của quá trình dinh dưỡng kém kéo dài do trẻ khó thở, viêm phổi tái diễn, bú kém và hấp thu không đầy đủ. Vaidyanathan B (2002) cho rằng đối với các nước đang phát triển (trong đó có Việt nam) thì tình trạng nghèo đói và hạn chế về kiến thức dinh dưỡng làm trầm trọng thêm dấu hiệu chậm phát triển của trẻ mắc TLT lỗ lớn. Tuy nhiên ông chỉ ra rằng tình trạng suy dinh dưỡng không làm tăng tỉ lệ tử vong sau mổ và phẫu thuật vá TLT lỗ lớn không nên bị trì hoãn bởi các nguyên nhân trên [20]. Đồng quan điểm trên, Servet Ergun (2019) và Schipper M (2017) cho rằng cân nặng thấp không làm tăng tỉ lệ tử vong sau mổ mặc dù thời gian thở máy và thời gian hồi sức dài hơn. [9] [19].

\section{Đặc điểm siêu âm tim trước mổ.}

Về vị trí TLT trên siêu âm tim (Bảng 3) phần lớn là TLT quanh màng $50 \mathrm{BN}(83,3 \%)$, phần phễu $6 \mathrm{BN}(10,0 \%)$, phần buồng nhận $1 \mathrm{BN}$ $(1,7 \%)$, phần cơ bè $2 \mathrm{BN}(3,3 \%)$, có $1 \mathrm{BN}$ TLT ở hai vị trí quanh màng và cơ bè $(1,7 \%)$ (Bảng 2$)$. Kết quả này của chúng tôi tương đương với nhiều nghiên cứu trong và ngoài nước, tổng hợp của Kirklin J. W (2003) tỉ lệ TLT quanh màng 75 $80 \%$, TLT phần phễu $5-10 \%$, TLT phần cơ bè 4 - 5\% [15]. Nguyễn Quang Minh (2018): tỉ lệ TLT phần quanh màng $(89,2 \%)$, phần phễu $(5,4 \%)$, phần buồng nhận $(1,8 \%)$, phần cơ $(3,6 \%)$ [1].

Kích thước lỗ thông trung bình trên siêu âm là 9,23 $\pm 3,32 \mathrm{~mm}(6-20 \mathrm{~mm})$ (bảng 2), đều là những lỗ thông kích thước lớn - rất lớn. không có khả năng tự đóng. Zhang $\mathrm{J}$ (2015) cho rằng những lỗ thông kích thước $>6 \mathrm{~mm}$ rất ít có khả năng tự đóng [21], điều này hoàn toàn phù hợp với chỉ định phẫu thuật và diễn tiến của bệnh, $\mathrm{y}$ văn trước giờ đã khẳng định kích thước luồng thông, dòng máu lên phổi là một trong những yếu tố quan trọng thúc đẩy tiến trình TALĐMP, Ngọ Văn Thanh, Nguyễn Lân Hiếu (2010) cho rằng $50 \%$ TLT lớn sẽ nhanh chóng tiến triển thành hội chứng eisenmenger [4].

ALĐMPTT đo trên siêu âm - Doppler tim trung bình là $71,53 \pm 9,42 \mathrm{mmHg}$, tất cả $60 \mathrm{BN}$ ALĐMPTT đều $>50 \mathrm{mmHg}$ (Bảng 3). Trong đó có tới 53,3\% ALĐMPTT tăng rất nặng $>70$ mmHg. Sự thay đổi kích thước các buồng tim được ghi nhận trên siêu âm - Doppler tim: Đường kính thất trái tâm trương và đường kính gốc ĐMP giãn to (Z-score trung bình lần lượt là 2,19 và 3,04 ) (Bảng 3). Những dấu hiệu trên đã phản ánh trung thực tình trạng TALĐMP ở nhóm $\mathrm{BN}$ được nghiên cứu. BN bị TLT ban đầu biểu hiện suy tim trái thể hiện trên siêu âm là đường kính thất trái cuối tâm trương giãn, do shunt T-P gây máu lên phổi nhiều $=>$ máu về thất trái nhiều trong thời kì tâm trương $=>$ thất trái sẽ giãn theo cơ chế Frank - Starling.

\section{3. Đặc điểm trong phẫu thuật}

Tất cả 59 bệnh nhân trong nghiên cứu đều được mổ duới THNCT thuờng quy (Bảng 4), liệt tim bằng dung dịch Custadiol lạnh borm qua gốc $Đ M C$ vào ĐM vành theo kiểu xuôi dòng, ha thân nhiệt về $32^{\circ} \mathrm{C}$, nhiệt độ phòng mổ $20-22^{\circ} \mathrm{C}$.

Thời gian chạy tuần hoàn ngoài cơ thể trung bình là $67,8 \pm 24,5$ phút, ngắn nhất 30 phút, lâu nhất là 120 phút. Thời gian cặp ĐMC ngắn nhất là 15 phút, lâu nhất là 90 phút, trung bình là 
44,3 $\pm 20,4$ phút. Kết quả của chúng tôi không khác biệt nhiều so với nghiên cứu của Schipper M (2017) trên 243 bệnh nhân: thời gian THNCT $63,5 \pm 22,5$ phút, thời gian cặp ĐMC 41,2 $\pm 18,1$ phút [19], Bùi Đức Phú (2006): các giá trị trên lần lượt là $67,8 \pm 18,40$ phút và $46,3 \pm 15,80$ phút, cũng như nghiên cứu của Lê Ngọc Thành (2007): $72,0 \pm 25,4$ phút và $53,4 \pm 23,2$ phút. Điều đó cho thấy sự thành thạo trong kĩ thuật mổ đóng TLT ở tất cả các trung tâm phẫu thuật tim mạch trong nước.

\section{Kết quả phẫu thuật}

Biến chứng sau mổ (Bảng 5):

Tỉ lệ biến chứng shunt tồn lưu sau mổ trong nghiên cứu của chúng tôi là $14 \mathrm{BN}(23,7 \%)$, trong đó $11 \mathrm{BN}$ là shunt nhỏ dạng thấm kích thước $1-2$ mm, không ảnh hưởng tới tình trạng huyết động do đó những trẻ này chỉ cần được theo dõi định kỳ. $3 \mathrm{BN}$ còn lại kích thước shunnt $>2 \mathrm{~mm}$ đều được lên kế hoạch theo dõi cùng với đó cần được dự phòng viêm nội tâm mạch nhiễm khuẩn. Tỉ lệ shunt tồn lưu cũng rất dao động trong nhiều nghiên cứu từ $10-30 \%$ [15]. Nguyễn Quang Minh (21,8\%) [1]. Maartje Shipper (2017) báo cáo tỷ lệ shunt tồn lưu cao $(51 \%)$, điều này được giải thích do nghiên cứu của ông thực hiện siêu âm qua thực quản để theo dõi bệnh nhân, độ chính xác rất cao giúp phát hiện những shunt tồn lưu thậm chí rất nhỏ đã được kết luận là bình thường trên siêu âm qua thành ngực, ông thấy rằng hầu hết shunt $(71 \%)$ đều tự đóng sau trung bình 3,1 năm. Dodge-Khatami (2007) nghiên cứu trên $198 \mathrm{BN}$ có shunt tồn lưu sau mổ đã chỉ ra rằng $83 \%$ shunt tồn lưu có kích thước $\leq 2 \mathrm{~mm}$ sẽ tự đóng trong 1 năm. Ngược lại những shunt kích thước $>2 \mathrm{~mm}$ ít có khả năng tự đóng, cần can thiệp khi gây ảnh hưởng đến tình trạng huyết động.

Biến chứng chảy máu sau mổ phải mổ lại chúng tôi gặp ở $2 \mathrm{BN}(3,4 \%)$, cả 2 trường hợp này nguyên nhân chảy máu đều từ chân chỉ khâu xương ức, và đều được cứu sống. Nhiễm trùng vết mổ $8,5 \%$, những bệnh nhân này đều được làm sạch và khâu lại vết mổ sau đó đều ổn định. 1 bệnh nhân có cơn tăng áp phổi được điều trị bằng sidenafil đường tĩnh mạch, không có $\mathrm{BN}$ nào bị viêm xương ức. Các biến chứng nặng nề: suy hô hấp, hội chứng cung lượng tim thấp, suy đa tạng trong nghiên cứu của chúng tôi không gặp trường hợp nào.

2 bệnh nhân bị liệt cơ hoành sau mổ (3,4\%), Charles D. Fraser (2021) đã tổng hợp nghiên cứu trên 126 trung tâm phẫu thuật tim mạch cho thấy tỷ lệ biến chứng này gặp trong phẫu thuật tim bẩm sinh từ $0,3 \%$ đến $12,8 \%$, và có liên quan tới thời gian thở máy, thời gian nằm viện kéo dài [10]. Cả $2 \mathrm{BN}$ của chúng tôi sau đó được khâu gấp nếp cơ hoành và không có biểu hiện suy hô hấp khi ra viện

Biến chứng rối loạn nhịp tim block AV III có đặt máy tạo nhịp chúng tôi gặp ở $1(1,7 \%)$, tỷ lệ tương đương với nghiên cứu của Stephanie $L$ (2013) trên 828 BN được phẫu thuật TLT, 1,9\% có block AV III yêu cầu đặt máy tạo nhịp [18]. Tỷ lệ gặp cao hơn trong nghiên cứu của Nguyễn Quang Minh (2018) và Aydemir N. A (2013) không có $\mathrm{BN}$ nào block nhĩ thất hoàn toàn [1] [6]. Qua kết quả nghiên cứu của chúng tôi và các tác giả trên có thể thấy Block nhĩ - thất hoàn toàn, một biến chứng đáng sợ sau vá TLT chiếm tỷ lệ nhỏ, điều này hoàn toàn phù hợp với kết luận của $H$. Andersen (2006) khi nghiên cứu biến chứng trên ở 
nhiều trung tâm phẫu thuật tim lớn trên thế giới tỉ lệ biến chứng này là khoảng $1 \%$, nguyên nhân không phải do lỗi của thầy thuốc gây lên mà là do những bất thường về đường đi của hệ thống dẫn truyền không thể nhận biết được trong khi mổ [7].

Biến chứng block nhánh phải chúng tôi gặp ở 17 bệnh nhân $(28,4 \%)$, tương tự với kết quả nghiên cứu của Brandy B.S (2010) là $26 \%$ [17], Tỷ lệ biến chứng này được Kirklin và BarrattBoyes tổng hợn trong cuốn Cardiac Surgery có thể lên tới 44 - $80 \%$ : (Gelband 80\%), Weidman (44\%), Rein (34\%) [15]. Qua kết quả tổng hợp các nghiên cứu cho thấy biến chứng này ít xảy ra hơn khi tiếp cận vá thông liên thất qua đường tâm nhĩ phải và đây cũng là đường tiếp cận phổ biến nhất trong nghiên cứu của chúng tôi. Các theo dõi lâu dài về ảnh hưởng của $\mathrm{RBBB}$ đối với chức năng tim, Thais $\mathrm{AL}$ Pedersen (2008) cho rằng RBBB theo dõi lâu dài dường như không ảnh hưởng đến chức năng tâm thu nhưng có thể liên quan đến rối loạn chức năng tâm trương [16], Cem Karadeniz (2015) đưa ra nhận xét RBBB trong các trường hợp phẫu thuật sửa chữa VSD có thể liên quan đến rối loạn chức năng thất phải [14]. Sau cùng thì Block nhánh phải sau phẫu thuật đóng VSD vẫn là một biến chứng phổ biến nhất và cần được đánh giá lâu dài.

\section{Tử vong bệnh viện: (bảng 6)}

Trong tổng số 59 trẻ được phẫu thuật có 1 trẻ tử vong sớm $(1,7 \%)$. $\mathrm{BN}$ mắc hội chứng Down kèm theo tắc tá tràng bẩm sinh đã phẫu thuật trước mổ, thể trạng yếu, cân nặng trước phẫu thuật là $2,7 \mathrm{~kg}$, tuổi $>1$ tháng. TLT lớn TALĐMP rất nặng - suy tim không đáp ứng với điều trị nội khoa. Tử vong ngày thứ 9 sau mổ, nguyên nhân là do sốc nhiễm khuẩn.
Tỉ lệ tử vong bệnh viện trong nghiên cứu của chúng tôi là $1,7 \%$ (bảng 6 ), tương tự như kêt quả trong nghiên cứu của Aydemir N. A $(1,4 \%)$ [6], Anderson B.R (2013) 1,4\% [8], tỉ lệ này thấp hơn trong nghiên cứu của Vaidyanathan $\mathrm{B}$ (2002) 6\% [20], Bùi Đức Phú (4,8\%), Lê Minh Sơn $(5,7 \%)$ [3]. Điều này có thể do trong nghiên cứu của chúng tôi có tuổi trung bình khi phẫu thuật thấp (trung bình 8,98 tháng), trong nghiên cứu của Aydemir N. A là $<1$ tuổi, Andreson là 144 ngày (4,8 tháng), giai đoạn này áp lực động mạch phổi tăng do shunt, chưa đến giai đoạn tăng cố định. Tuổi thấp hơn so với các nghiên cứu khác như Lê Minh Sơn (trung bình 41 tháng) [3]. Phù hợp với quan điểm phẫu thuật thời điểm $<1$ tuổi mang lại kết quả khả quan hơn đã được chứng minh trong nghiều nghiên cứu [9] [6]. Cùng với đó, hiện nay chuyên ngành phẫu thuật tim hở ngày càng phát triển, phương pháp bảo vệ cơ tim rất tốt cùng với các trang thiết bị hỗ trợ ngày càng hiện đại, trình độ chuyên môn của phẫu thuật viên được nâng cao và chăm sóc hậu phẫu tốt, đem lại kết quả phẫu thuật tốt nhất cho người bệnh.

\section{Siêu âm khi khám lại.}

AĐMPTT trung bình khi khám lại 23,96 土 $7,53 \mathrm{mmHg}$, giảm rất rõ so với thời điểm trước mổ $(71,41 \pm 9,14)$ và khi ra viện $(33,18 \pm 10,27)$ có ý nghĩa thông kê, $\mathrm{p}<0,05$ (bảng 6). Kết quả này phù hợp với lâm sàng, diễn tiến sau mổ của bệnh nhân TLT - TALĐMP nặng, giai đoạn đầu ALĐMP tăng là do shunt T-P, chưa tiến triển đến giai đoạn tăng cố định, nên sau khi phẫu thuật, không còn shunt $=>$ ALĐMP giảm nhanh. So sánh với nghiên cứu Lê Minh Sơn (2008) với kêt quả ALĐMP trung bình trước mổ/ra viện/khi tái 


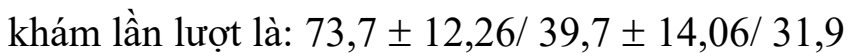
$\pm 6,52$ thì thấy ALĐMP khi ra viện và khi tái khám của chúng tôi thấp hơn. Sở dĩ có sự khác biệt vậy là do lứa tuổi trung bình trong nghiên cứu của chúng tôi là $8,98 \pm 20,45$ tháng, nhỏ hơn nhiều so với lứa tuổi được phẫu thuật trong nghiên cứu của Lê Minh Sơn là 41,1 $\pm 43,01$ tháng [3]. Hiện nay, nhằm điều trị triệt để hậu quả của bệnh lí tăng ALĐMP trên tuần hoàn phổi, nhiều tác giả khuyến cáo nên mổ đóng TLT có tăng ALĐMP sớm hơn nữa trong vòng năm đầu của cuộc sống: Aydemir N. A [6], Ergun S [9].

Trong nhóm BN nghiên cứu của chúng tôi, ALĐMPTT trung bình khi tái khám của nhóm $\mathrm{BN}$ được mổ đóng TLT trước 12 tháng tuổi là $22,96 \pm 6,14 \mathrm{mmHg}$, thấp hơn rõ rệt so với nhóm được mổ sau 12 tháng tuổi $30,0 \pm 11,1(\mathrm{p}<$ 0,05). Tỉ lệ ALĐMP trở lại bình thường sau mổ ở nhóm trẻ được mổ trước 12 tháng tuổi là 89,6 \% cao hơn nhiều so với nhóm trẻ được mổ sau 12 tháng tuổi là 50,0\% $(\mathrm{p}<0,05)$. (Bảng 7) Có thể nói đây là minh chứng cho lợi ích của việc mổ đóng TLT sớm trước 12 tháng tuổi.

Tình trạng suy tim và suy dinh dữ̃ng khi

\section{khám lại}

Sự cải thiện của tình trạng lâm sàng biểu hiện rõ nét qua sự thay đổi tỉ lệ BN theo phân độ suy tim và suy dinh dưỡng giữa 2 thời điểm trước mổ và khi khám lại (bảng 8 ).

Trong đó khi khám lại, phần lớn bệnh nhân có suy tim độ 1 (91,1\%), chỉ có 5 bệnh nhân (8,9\%) suy tim độ II-III. Không có bệnh nhân nào suy tim độ IV. Có sự khác biệt hoàn toàn so với lúc trước mổ $(\mathrm{p}<0,001)$ (bảng 8$)$. Kết quả nghiên cứu ghi nhận có 5 trường hợp suy tim mạn 2 trở lên đang theo dõi và điều trị nội khoa. Tình trạng suy tim của nhóm bệnh nhân này là do còn tình trạng tăng áp lực động mạch phổi dai dẳng sau mổ, tất cả các trường hợp này trước mổ đều có mức áp lực ĐMP tăng rất nặng $(>70 \mathrm{mmHg})$. Các trường hợp này đều được lên kế hoạch điều trị nội khoa gồm thuốc điều trị suy tim, hạ áp phổi và theo dõi định kỳ.

Tình trạng dinh dưỡng của $\mathrm{BN}$ cũng thấy sự thay đổi rất rõ rệt. Đa số các trẻ đã không còn tình trạng suy dinh dưỡng $(73,2 \%)$ tại thời điểm khám lại (theo phân loại suy dinh dưỡng của WHO 2006 dựa trên cân nặng và tuổi), chỉ còn 15 trẻ (26,8 \%) còn suy dinh dưỡng mức độ vừa - nặng, đó đa phần là những trẻ đẻ non, cân nặng lúc sinh thấp hơn so với tuổi thai và nhóm trẻ lớn đã SDD trong 1 thời gian dài trước đó. 3 tháng sau mổ đều tăng cân nhưng tính Zscore cân nặng theo tuổi vẫn nằm trong nhóm suy dinh dưỡng, để đánh giá tình trạng dinh dưỡng của nhóm trẻ này cần có thêm thời gian để theo dõi. Vaidyanathan $\mathrm{B}$ và cộng sự (2002) đã tiến hành phẫu thuật cho 100 trẻ có TLT lỗ lớn với độ tuổi trung bình $7.4 \pm 3.3$ tháng, Zscore cân nặng theo tuổi trung bình: -2.8 \pm 1.3 cũng cho kết quả rất khả quan [20]. Qua đây cho thấy việc phẫu thuật sớm cho trẻ TLT ngoài tránh được những biến chứng tim mạch còn giúp cho sự phát triển bình thường của trẻ.

\section{KẾT LUẬN}

Phẫu thuật vá lỗ TLT - TALĐMP nặng được thực hiện tại TTTM-BVE cho kết quả ban đầu rất tốt, tỷ lệ thành công $98,3 \%$. Các biến chứng được phát hiện và xử trí kịp thời. Các triệu chứng lâm sàng và siêu âm tim được cải thiện rõ rệt đặc biệt ở nhóm trẻ được phẫu thuật trước 12 tháng tuổi. 


\section{TÀI LIỆU THAM KHẢO}

1. Nguyễn Quang Minh (2019), Đặc điểm lâm sàng, cận lâm sàng và đánh giá kết quả điều trị phẫu thuật vá thông liên thất ở trẻ có cân nặng $\leq 5 \mathrm{~kg}$ tại trung tâm tim mạch bệnh viện E, Luận văn Thạc sĩ Y học, Đại học Y Hà Nội.

2. Tăng Hùng Sang và Vũ Minh Phúc (2010), "Đặc điểm của trẻ thông liên thất được phẫu thuật tại Bệnh viện Nhi đồng 1", Tạp chí Y học Thành phố Hồ Chí Minh. 1.

3. Lê Minh Sơn (2007), Nghiên cứu đặc điểm lâm sàng, cận lâm sàng và kết quả điêu trị thông liên thất có tăng áp lục động mạch phổi nặng ở trẻ em tại Bệnh viên Việt Đức, Luận văn Thạc sĩ Y học, Đại học Y Hà Nội.

4. Ngọ Văn Thanh, Nguyễn Lân Hiếu và Nguyễn Văn Mão (2010), "Tăng áp phổi trong bệnh lý tim bẩm sinh trẻ em", Bệnh viện Tim Hà Nội, Viện Tim mạch Việt Nam.

5. Đào Hữu Trung và Phạm Nguyễn Vinh (Thông Liên Thất), Bệnh học tim mạch, Nhà xuất bản Y học Hà Nội.

6. Aydemir N. A, Karaci A. R , Harmandar B and et al (2013), "Results for surgical closure of isolated ventricular septal defects in patients under one year of age", Journal of Cardiac Surgery: Including Mechanical and Biological Support for the Heart and Lungs. 28(2), pp. 174-179.

7. Andersen H, Tsang V. T , Leval D and et al (2006), "Is complete heart block after surgical closure of ventricular septum defects still an issue?", The Annals of thoracic surgery. 82(3), pp. 948-956.

8. Anderson B. R, Nicolson S. C, Stevens K. N and et al (2013), "Contemporary outcomes of surgical ventricular septal defect closure", The Journal of thoracic and cardiovascular surgery. 145(3), pp. 641-647.

9. Ergun S, Yildiz O, Genc, S. B and et al (2019), "Risk factors for major adverse events after surgical closure of ventricular septal defect in patients less than 1 year of age: a single-center retrospective", Brazilian journal of cardiovascular surgery. 34, pp. 335-343.

10. Fraser III C. D, Thibault D, Ravekes W và and al (2021), "Diaphragm paralysis after pediatric cardiac surgery: An STS Congenital Heart Surgery Database study", The Annals of Thoracic Surgery. 112(1), pp. 139-146.

11. Ikawa S, Nakano S, Shimazaki $\mathrm{Y}$ and et al (1995), "Pulmonary vascular resistance during exercise late after repair of large ventricular septal defects: Relation to age at the time of repair", The Journal of thoracic and cardiovascular surgery. 109(6), pp. 1218-1224.

12. Jortveit J, Eskedal L, Leirgul $\mathrm{E}$ and et al (2016), "Mortality and complications in 3495 children with isolated ventricular septal defects", Archives of disease in childhood. 101(9), pp. 808-813.

13. Kogon B, Butler H, Kirshbom $P$ and et al (2008), "Closure of symptomatic ventricular septal defects: how early is too early?", Pediatric cardiology. 29(1), pp. 36-39.

14. Karadeniz C, Demir F , Atalay S and et al (2015), "Does surgically induced right bundle branch block really effect ventricular function in children after ventricular septal defect closure?", Pediatric cardiology. 36(3), pp. 481-488. 
15. Kirklin J. W and Barratt B.G (2003), "Ventricular septal defect", Cardiac Surgery, pp. 1262.

16. Pedersen T. A, Knudsen M. R, Andersen N. $\mathrm{H}$ và and al (2008), "The effects of surgically induced right bundle branch block on left ventricular function after closure of the ventricular septal defect", Cardiology in the Young. 18(4), pp. 430-436.

17. Scully B. B, Zafar F, David L. S and et al (2010), "Current expectations for surgical repair of isolated ventricular septal defects", The Annals of thoracic surgery. 89(2), pp. 544-551.

18. Siehr S. L, Reddy, V. M ,Hanley F. L and et al (2014), "Incidence and risk factors of complete atrioventricular block after operative ventricular septal defect repair", Congenital heart disease. 9(3), pp. 211-215.

19. Schipper M, Slieker M. G, Schoof P. H and et al (2017), "Surgical repair of ventricular septal defect; contemporary results and risk factors for a complicated course", Pediatric cardiology. 38(2), pp. 264-270.

20. Vaidyanathan B, Rao S. G, Roth S. J and et al (2002), "Outcome of ventricular septal defect repair in a developing country", The Journal of pediatrics. 140(6), pp. 736-741.

21. Zhang J, Guileyardo J. M, Ko J. M and et al (2015), A review of spontaneous closure of ventricular septal defect, Baylor University Medical Center Proceedings, Taylor \& Francis, pp. 516-520. 